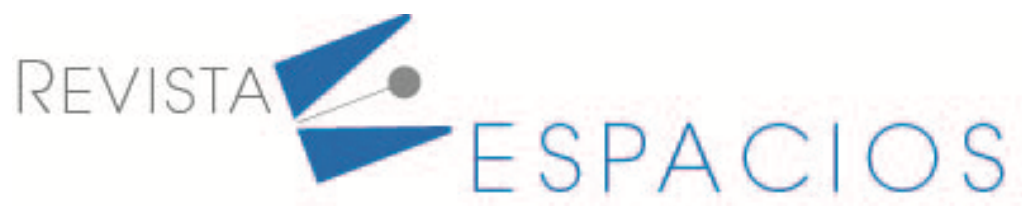

\title{
Uso de equipos de teledetección para analizar condiciones de movilidad en asentamientos carenciados
}

\section{Use of remote sensing equipment to analyze mobility conditions in slums}

\author{
URAZÁN-BONELLS, Carlos F. ${ }^{1}$ \\ CAICEDO -LONDOÑO, María A. ${ }^{2}$ \\ RINCÓN-ARANGO, Orlando ${ }^{3}$ \\ AGUDELO-RODRÍGUEZ, Carlos F. ${ }^{4}$ \\ SANABRIA-BUITRAGO, Mayerling ${ }^{5}$
}

\begin{abstract}
Resumen
Se realizaron pruebas piloto con diversos equipos de teledetección para establecer la condición de varios aspectos en infraestructura y transporte en un sector urbano de origen informal. El uso de: imágenes satelitales, fotografías, videos, drones, radar de velocidad, y equipos de GPS para el reconocimiento de la condición del terreno y del tránsito; agiliza la obtención de información técnica para concluir la necesidad o no de estudios de mayor detalle, en pro de un proceso de potencial legalización urbanística.

Palabras clave: asentamientos informales, movilidad, teledetección.
\end{abstract}

\begin{abstract}
Pilot tests were carried out with various remote sensing equipment to establish the condition of various aspects of infrastructure and transport in an urban sector of informal origin. The use of: satellite images, photographs, videos, drones, speed radar, and GPS equipment for the recognition of the condition of the terrain and traffic; expedites the obtaining of technical information to conclude the need or not for more detailed studies, in favor of a process of potential urban legalization.

Key words: informal settlements, mobility, remote sensing
\end{abstract}

\footnotetext{
${ }^{1}$ Ingeniero Civil, Esp. en Administración de Obras de Construcción. PhD. En Gestión Territorial e Infraestructura del Transporte. Docente investigador del programa de Ingeniería Civil de la Universidad de La Salle, Bogotá, Colombia. Email: caurazan@unisalle.edu.co.

2 Ingeniero Civil. Magister. Docente investigador del programa de Ingeniería Civil de la Universidad de La Salle, Bogotá, Colombia. Email: macaicedo@unisalle.edu.co.

${ }^{3}$ Ingeniero Civil, PhD Ingeniería. Docente investigador del programa de Ingeniería Civil de la Universidad de La Salle, Bogotá, Colombia. Email: orincona@unisalle.edu.co.

${ }^{4}$ Arquitecto. Magister Docente investigador del programa de Arquitectura y urbanismo de la Universidad de La Salle, Bogotá, Colombia. Email: cfagudelo@unisalle.edu.co.

${ }^{5}$ Ingeniera Ambiental y Sanitaria. Magíster en Hábitat. Especialísta en Sistemas de Información Geográfica y sensores remotos. Especialista en evaluación de impacto ambiental en proyectos. Docente investigador del programa de Ingeniería Ambiental y Sanitaria de la Universidad de La Salle, Bogotá, Colombia. Email: msanabria@unisalle.edu.co.
} 


\section{Introducción}

El desarrollo informal en las distintas regiones del mundo ha sido ampliamente estudiado por sociólogos, economistas, urbanistas, arquitectos e ingenieros; cada uno en su rama particular del conocimiento. Sin embargo, todos los estudios tienen en común la tendencia del origen de la informalidad urbana. Los denominados barrios marginales son un fenómeno mundial, y se han manifestado desde hace décadas en diversas tipologías y configuraciones, tanto geográficas como evolutivas en cuanto a desarrollo urbano, de vivienda y de servicios (UN-Habitat, 2006). El fenómeno de estos desarrollos humanos informales, también denominados en diversos ámbitos y regiones como: asentamientos carenciados o incompletos, favelas o slums, son una realidad desde hace cientos de años, y siguen requiriendo de soluciones para agilizar un cambio en sus condiciones. Actualmente viven en sectores informales urbanos cerca de 1 billón de personas que son parte de la gran expansión urbana (Lincoln Institute of Land Policy, 2019).

Los asentamientos carenciados son áreas residenciales en las que sus habitantes no cuentan con los derechos de ocupación del terreno, ni permisividad técnica sobre las edificaciones allí realizadas. La descripción de los elementos desencadenantes de este tipo de asentamientos se estudia desde hace varias décadas, y puede encontrarse en documentos como Urazán (2008), y Clichevsky (2000), así como en notas de programas y entidades como: Bogotá cómo vamos (s.f.), y el Lincoln Institute of Land Policy (2006). También hay estudios complementarios que han evaluado la evolución de estos sectores hacia condiciones formales (Urazán y Magrinyá, 2015).

Estos sectores también suelen carecer de acceso a servicios públicos oficiales, así como de infraestructura urbana. Como se mencionó, sus edificaciones no han surtido el proceso de legalización constructiva, y suelen ubicarse en terrenos con riesgo, tales como deslizamientos de tierra o inundaciones (ONU, 2015).

Entre las diversas condiciones carenciadas de este tipo de asentamientos están:

- No hay propiedad predial.

- Abastecimiento de agua para consumo en condiciones inadecuadas.

- Condiciones deficitarias de saneamiento.

- Terrenos en condiciones de riesgo.

- Edificaciones con materiales precarios.

- Accesibilidad en malas condiciones de infraestructura y tiempo de desplazamientos a trabajo o estudio.

Este artículo está fundamentado en el proyecto "Apropiación de herramientas para teledetección en el reconocimiento de condiciones urbanísticas en asentamientos carenciados", desarrollado por los autores del presente escrito, bajo el amparo financiero e institucional de la Vicerrectoría de Investigación y Transferencia (VRIT), de la Universidad de La Salle, łBogotá). El objetivo del proyecto es poner de manifiesto la posibilidad de realizar estudios que diagnostiquen las carencias en vivienda e infraestructura básica, con resultados técnicamente fiables, realizados en un breve lapso de tiempo, que permitan establecer la necesidad de un estudio definitivo. En el presente artículo se hará énfasis en las condiciones de transporte y movilidad.

\subsection{Condiciones de movilidad en asentamientos carenciados}

La movilidad de los distintos actores de la sociedad es fundamental para un adecuado desarrollo económico y social. Los mecanismos o infraestructura para facilitar la movilidad a la gente, especialmente en centros urbanos, requiere de inversión pública y la participación de entidades privadas como empresarios del sector transporte, para sí poder brindar un sistema de transporte público eficiente que se identifique con criterios como:

- Tiempo adecuado de transporte desde y hacia las rutas de transporte público urbano. 
- Geometría adecuada en la red vial del asentamiento para facilitar el paso de vehículos de transporte público y de emergencia.

- Servicio de transporte público hacia y desde la zona central del casco urbano, a precio razonable.

- Condición de rodadura en las vías del asentamiento, que no se vean afectadas por fuertes pendientes y por efectos de aguas de escorrentía.

- Disposición de senderos peatonales seguros.

Como se ha establecido en párrafos precedentes, las condiciones de localización, orografía e ilegalidad de los asentamientos carenciados; no facilitan el acceso vehicular, y hacen complicado el trayecto peatonal. Algunas iniciativas como el programa Morar Carioca, aplicado en las favelas de Río de Janeiro, han encontrado como principal problema el acceso a la información de cómo se movilizan las personas. Por tanto, la metodología aplicada se basa en la realización de encuestas a habitantes de diferentes favelas, asemejando la realización de las denominadas Encuestas Origen - Destino. Entre la información obtenida se tiene la tasa de posesión vehicular con el valor más alto para bicicletas, seguido por carros y por motocicletas. Esa tasa de posesión se discriminó también por género, edad, nivel de ingresos económicos y nivel educativo. También se identificó el porcentaje de vehículos con registros legales en orden y el porcentaje de conductores con licencia. Adicionalmente se indagó por los lugares en que suelen estacionar los vehículos, tanto para carros como para motocicletas; y por la selección modal para desplazarse al interior de la favela, y fuera de ella; así como el porcentaje de viajes que tardan más de 30 minutos. El estudio finaliza con un análisis comparado entre las condiciones de movilidad de los habitantes de las favelas, y los de la región metropolitana de Río de Janeiro; dando como principal dato un porcentaje notablemente mayor de la modalidad peatón en las favelas, así como una menor participación del bus urbano, y claro está, del automóvil (Koch, Lindau \& Nassi, 2013).

En otro estudio, también aplicado en Río de Janeiro, pero esta vez a los barrios del programa estatal de vivienda social Minha Casa Minha Vida (MCMV), y no a asentamientos de origen informal. El documento llega a conclusiones similares al de Morar Carioca sobre la selección modal de los habitantes para realizar sus viajes, tras haber abordado una metodología similar de encuestas origen - destino (Nadal \& Linka, 2018).

En otras regiones del mundo, diversos estudios definen como se presenta el transporte urbano en asentamientos humanos en condiciones de pobreza. Por ejemplo, Gulyani, Talukdar \& Jack (2010) concluyen que en asentamientos informales en Dakar, Johannesburgo y Nairobi, hay poca participación en el número de viajes realizados en vehículos motorizados, y una mayor participación de viajes a pie.

En otro estudio, Renny, M. (2009) presenta el análisis de 5 asentamientos informales en Indonesia para comprender las necesidades de transporte de la gente, indagando por sus destinos, horarios de viaje, sus motivos, y los cambios que manifestaban los encuestados (mayores a 15 años de edad). Starkey \& Hine (2014) mencionaron tras un estudio en 18 ciudades africanas, que la población más pobre gasta entre el $4 \%$ y el $10.6 \%$ de sus ingresos en transporte, pues caminan en la mayoría de los casos; seguramente por necesidad de ahorro. Al ir incrementando el nivel de ingresos, la proporción empleada en transporte aumenta.

En todos los estudios mencionados queda clara la relación que hay entre condiciones de transporte y pobreza. Establece criterios de planificación en transporte para diversos tamaños poblacionales, enfocándose en la necesidad de reducir costos y tiempos de viajes para mejorar la calidad de vida de la población más vulnerable.

Vale la pena resaltar la importancia de este tipo de estudios, pues las encuestas de origen - destino realizadas por los entes administrativos, no suelen cobijar consultas en sectores no legalizados.

Estudiar las condiciones de viaje y movilidad de la gente a partir de sus patrones de viaje es indiscutiblemente importante para poder planear el cómo servir a la población de la periferia urbana con un transporte público 
adecuado. No obstante, para que ese transporte se preste adecuadamente a la población de esos sectores potencialmente formalizables o legalizables, hay que conocer las características básicas de su topografía e infraestructura incipiente; con el fin único de facilitar el ingreso de vehículos, especialmente de transporte público, y minimizar los tiempos de viaje de la población que ha de transitar a pie. Lo anterior, aunado a condiciones de seguridad.

\subsection{Localización, topografía y trazado como limitaciones a la red de accesibilidad}

La diferencia entre la complejidad de la movilidad en zonas rurales y las urbanas, para las personas de más escasos recursos, es notoria. Cabe recordar que para 2030 se espera que la población urbana mundial ascienda a 4.9 billones de personas. En el caso latinoamericano, se tiene una de las más altas tasas de desigualdad, en donde 104 millones de personas viven en asentamientos irregulares o informales (Techo, s.f.).

En algunas zonas urbanas las condiciones viales para vehículos y peatones son deficientes, especialmente en temporadas de lluvia. Parte de esas vías son proyectadas y ejecutadas por comunidades pobres en zonas de desarrollo ilegal. En gran parte de los casos, en los primeros años de iniciado el asentamiento informal, las vías de acceso son en tierra (Imagen 1), y con el paso de los años estas mejoran y pasan a ser vías construidas con la participación de habitantes de la comunidad (Imagen 2). Una vez legalizado el asentamiento, la administración municipal mejorará la condición de las vías de acceso principales (Urazán, 2008).

Pero lo que complica la situación de una infraestructura de transporte inadecuada es el gran tiempo de viaje que requieren los habitantes para cumplir con un horario laboral y los problemas que allí se derivan. Pero no solo son temas de acudir a tiempo al trabajo para procurar estabilidad e ingresos económicos, también es de vital importancia la puntualidad en la escolaridad, así como que el acceso vehicular no sea tan complejo que dificulte el aprovisionamiento de víveres de canasta básica, o el ingreso a la zona por parte de vehículos de emergencia médica o de seguridad (Starkey \& Hine, 2014). Claro está que la condición topográfica aumenta la complejidad del trazado vial (Imagen 3).

Imagen 1

Vía en tierra. Asentamiento de origen informal. Altos del Pino, Soacha. Colombia.

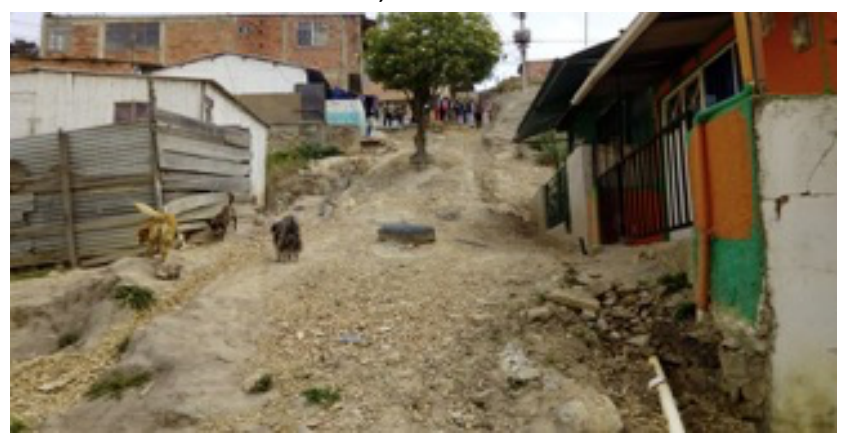

Fuente: Autores, 2018 
Imagen 2

Residentes trabajando en la conformación de una vía, en el sector informal Kanza, en la periferia de ciudad de Tirana, Albania.

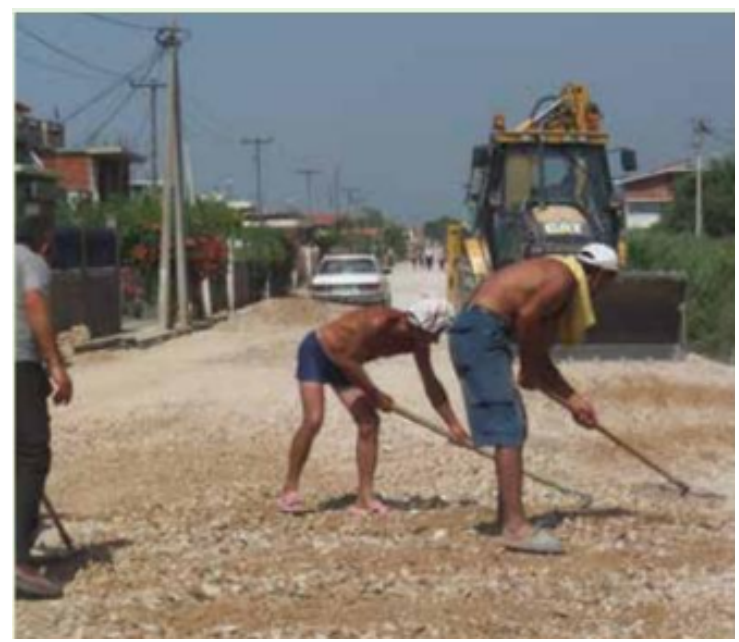

Fuente: UNHabitat, 2012

Imagen 3

Sectores de origen informal (Cúcuta, Colombia), con condiciones topográficas de difícil accesibilidad. Ubicados en inmediaciones del anillo vial occidental.

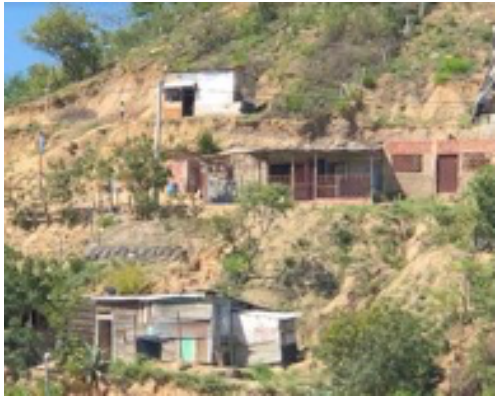

a. Sector El Salado

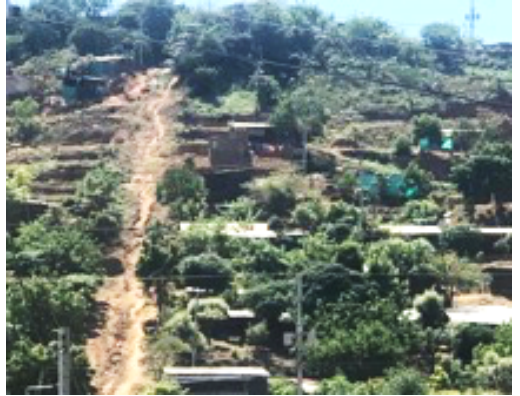

b. Sector Simón Bolívar

Fuente: Autores, 2019

\subsection{Teledetección como ayuda para identificar condiciones de accesibilidad}

Como ya se ha mencionado, los asentamientos de origen informal suelen tener condiciones de ubicación y topografía que no facilitan la accesibilidad, con la consecuencia de externalidades negativas sociales y económicas.

Para realizar una primera aproximación técnica que permita identificar diversas condiciones deficitarias de un asentamiento, puede recurrirse a visitas de campo que empleen equipos de teledetección y de fotografía, que recaben datos y mediciones de aspectos como: la ubicación del asentamiento en la mancha urbana, condiciones orográficas del terreno con medición de pendientes y longitudes de los tramos principales de acceso, materiales predominantes en la construcción de las viviendas, dimensionamiento exterior de las viviendas y separación entre predios, clasificación material de la capa de rodadura de las vías, localización de cuerpos de agua, entre otros aspectos. La idea es lograr una descripción técnica del lugar, sus viviendas e infraestructura disponible, como elemento para planeación de mejoras e intervenciones (si las conclusiones dan a lugar); esto antes de requerir estudios más detallados como un levantamiento topográfico para estimar diseños infraestructurales. 
El objetivo de la recolección de información preliminar (en algunos casos la información resulta definitiva) es agilizar el proceso de toma de decisiones a un costo más económico, pues podría concluirse del estudio preliminar que no vale la pena intervenir el asentamiento; y esto antes de realizar estudios en campo más complejos y costosos por su nivel de detalle.

Ahora, cabe aclarar que la teledetección es la manera de obtener información de objetos sin que los instrumentos empleados tengan contacto con el objeto en estudio. Por ejemplo, el análisis de los materiales que conforman una vivienda, a partir de una fotografía.

En diversidad de estudios se ha aplicado herramientas de teledetección y de Sistema de Información Geográfica SIG, como para: clasificación de suelos (Guillén, Murugan, y Dávila, 2014; Atencia, Contreras y Vergara, 2008), para el análisis de calidad del agua en embalses (Bazán et al, 2005), para la aplicación de un análisis de cambio del uso del suelo a una zona agrícola y pecuaria (Giraldo., 2013), para análisis de riesgo por inundación en cuenca de ríos (Alvarado, 2014), entre otros temas técnicos para planeación.

A la fecha se han realizado investigaciones y se han desarrollado proyectos que emplean mecanismos de teledetección para evaluar condiciones de accesibilidad y de mejora a asentamientos informales. Manzané, B; Fiol, I.; Camaño, N.; Vega, N. y Alarcón, J. (2019) analizaron vías de acceso a varios sectores de origen informal en la ciudad de Panamá. La metodología empleada recurre solamente a aplicativos como: Google Maps ${ }^{\circledR}$, Google Earth $^{\circledR}$, y $\operatorname{ArcGis}^{\circledR}$. No registran información directamente en campo. Las conclusiones se centran en que las vías de acceso a los asentamientos son senderos, que es difícil el acceso en temporada de lluvias, la cercanía de la vía de acceso con vías principales. También concluye la gran distancia entre el asentamiento y puntos de interés básico.

En otro documento (Borobio, 2009) se plantea la metodología para emplear herramientas SIG en la definición de las condiciones de un terreno en que se pueda instaurar un campo de emergencia para refugiados. Se trata de tareas de planificación territorial posteriores a la solución de temas como el sanitario, por ejemplo, la identificación de pozos o acuíferos, planear la densidad habitacional, estudiar las condiciones geológicas del entorno, la proximidad a redes eléctricas y carreteras, así como identificar las características topográficas.

Continuando con el estado del arte, Pérez (2009) expone la estrategia en el uso de herramientas SIG para mejorar la calidad de vida de habitantes de los barrios de Maputo (Mozambique), mediante la mejora en la provisión de servicios de agua y saneamiento, drenaje de aguas de lluvias y la pavimentación de vías. La información georreferenciada se complementó con encuestas a hogares y confirmación de data topográfica.

En la Universidad de Salzburgo (Austria) se llevó a cabo un trabajo final de maestría en el cual se aplicó SIG para las fases de: diagnóstico, evaluación y análisis territorial en un sector de la ciudad de Pereira con un gran número de viviendas de carácter informal. El fin último del estudio era identificar las zonas en que podría adelantarse el proceso de legalización. EI uso de SIG se complementó con encuestas a habitantes y con información de propiedad predial por parte de la Secretaría Municipal de Planeación. Una de las conclusiones principales es la necesidad de ampliar la vía principal de acceso al asentamiento (Tamayo, 2019).

\subsection{Propuesta de teledetección más allá del uso de imágenes remotas}

La mayoría de los análisis o estudios realizados, se centran en combinar imágenes remotas, a través de herramientas SIG, con encuestas a habitantes, para poder identificar las características relevantes de la zona que sirvan para planear el desarrollo urbanístico.

La propuesta que presenta el programa de Ingeniería Civil de la Universidad de La Salle complementa ese tipo de información con fotografías en campo, imágenes a partir de vuelo de drones, y registro de recorridos 
(tracking) en las rutas internas y de acceso al asentamiento, para establecer las condiciones de mejora que requiere la movilidad de los pobladores de un asentamiento carenciado. Para ello se llevó a cabo un ejercicio piloto en el barrio Carlos Pizarro, con el apoyo de estudiantes de final de carrera (Jurado y Zabala, 2019).

\section{Metodología}

\subsection{Identificación del sector a estudiar}

En el estudio de caso, se recurrió al sector denominado Carlos Pizarro, ubicado en el municipio de Soacha, que se encuentra en la zona regional circundante a la ciudad de Bogotá. Paso a seguir, se recopiló toda la información disponible respecto al asentamiento, y se gestionó el acompañamiento en campo por parte de líderes comunitarios. Cabe resaltar que el sector es un asentamiento con cierto grado de consolidación, hecho que da respaldo al estudio realizado por cuanto cuenta con potencial para ser legalizado.

\subsection{Recolección de información del terreno a partir de aplicaciones SIG de acceso libre}

La recolección de información base sobre el asentamiento se complementó con imágenes aéreas da partir de aplicativos que operan con Sistema de Información Geográfica SIG, como Google Earth y otros, con los cuales se pudieron establecer: medidas lineales, áreas, perímetros, identificación visual de edificaciones, vías, presencia de cuerpos de agua, y la distancia del asentamiento a vías principales u otros núcleos urbanos. Incluso se logró obtener información de perfiles de terreno e imágenes 3D. Cabe aclarar que esta información solo se empleó para establecer parámetros que definan una visión global de la situación del asentamiento. A pesar de que son varios los datos que se recopilaron del sector en estudio, es importante recordar que para este caso se analizaron solo condiciones de movilidad, es decir, no hubo concentración de información respecto de características de vivienda, ni de condiciones de agua, saneamiento u otros servicios básicos.

\subsection{Recolección de información de tramos de desplazamiento en vía mediante aplicaciones para seguimiento de rutas por GPS}

El trabajo de recolección de datos en campo se planeó en función de los equipos disponibles y la información requerida. Como ya se tenía identificada la vía principal de la cual se deriva el carreteable de acceso al asentamiento, la información a obtener se concentró en:

- La condición de pendiente media y máxima.

- Estado de la vía en cuanto ał su carpeta de rodadura.

- Perfil de la vía.

- Presencia de obras de arte para el drenaje de agua en la vía.

- Tiempo de viaje entre la vía principal y el asentamiento, tanto en vehículo como de manera peatonal.

De igual manera se procedió con las vías internas del asentamiento.

Para el registro de la información mencionada, las fotografías aéreas, a través de SIG, permitieron ubicar espacialmente la malla vial desarrollada por la comunidad.

Luego, para obtener datos de pendientes, distancias y velocidades medias de desplazamiento se recurrió a aplicativos para seguimiento, incorporados en el menú de los equipos GPS profesionales, y apoyándose en registros alternos mediante un aplicativo en teléfono móvil con GPS. Estos capturaban los datos mientras se realizaban los recorridos en tiempo real, entregando al final información como:

- Tiempo de recorrido

- Distancia de recorrido 
- Velocidad media del recorrido

- Velocidad máxima en el trayecto

- Gráfico de perfil de velocidades a lo largo del trayecto

- Mapa del trayecto

- Gráfico de perfil de elevación a lo largo del trayecto

- Fecha y hora de inicio y final del recorrido

Los recorridos se realizaron en diversos medios de transporte para tener información de cada uno. Cuando no hubo posibilidad de aplicar varios medios, se realizaron solo en automóvil y se extrapolaron tiempos y velocidades a peatón o bicicleta, basándose en estudios comparativos de velocidades según la pendiente de terreno.

En condiciones atmosféricas de lluvia al realizar el recorrido, la información resultante se consideró completa, pues se cuenta con registro del impacto que tiene la lluvia en los tiempos de viaje (de acuerdo a la intensidad registrada en el trayecto realizado).

De manera complementaria se empleó un radar de velocidades para registrar estos valores a lo largo de la vía de acceso al sector continuando por la vía principal.

\subsection{Captura de imágenes en campo}

Para el registro de imágenes en campo se recurrió a fotografías y a videos capturados por medio de un dron. El uso del dron agilizó el reconocimiento de las condiciones en que se encuentran las vías de acceso a las viviendas, especialmente las que se hayan más apartadas. Vale recordar que, de acuerdo al lugar donde se manipule el dron, hubo que revisar de antemano la existencia de normas que regulen su uso, para dar estricto cumplimiento.

\subsection{Encuesta a habitantes}

La encuesta a una muestra de la población permitió contrastar la percepción que tienen respecto de sus condiciones de movilidad y transporte, y así complementar la información capturada con equipos. El trabajo en campo para la toma de datos, incluyendo la realización de las encuestas, requirió de 3 jornadas, siendo un equipo de solo 2 personas. Claro está que eso conlleva un trabajo preliminar de contactos telefónicos con líderes de la comunidad, así como un reconocimiento previo del territorio en función de herramientas como Google Maps (y similares), e información de entidades del distrito u organizaciones de cooperación.

\subsection{Análisis y recomendaciones de intervención al asentamiento}

Como paso final se analizó la información recolectada para poder concluir las necesidades de mejora que requiere la comunidad a nivel de transporte, y su potencial ejecución. Las conclusiones pueden llevar a sugerir la necesidad de estudios más detallados como un levantamiento topográfico en caso de avanzar con un eventual proceso de legalización predial; o por el contrario, recomendar que no se avance en estudios por considerar que no se cumplen condiciones de no vulnerabilidad. Queda claro que para llegar a concluir respecto a la viabilidad de una posible legalización, se requiere de estudios de vulnerabilidad que van más allá de estudiar las condiciones de movilidad y transporte.

\section{Resultados}

\subsection{Imágenes de ubicación general y del trayecto de acceso al sector}

Empleando imágenes de Google Maps y Google Earth, se pudo establecer la ubicación y trazado de la vía de acceso al asentamiento Carlos Pizarro, así como sus condiciones básicas de infraestructura (imágenes 4,5 y 6). 
Los registros permitieron identificar que la mayor parte del trayecto no tiene tratamiento de carpeta, que la condición peatonal es compleja por alta pendiente y escasa presencia de andenes. No se aprecian obras para el manejo de escorrentías, lo cual dificulta la accesibilidad en temporada de lluvias. Si hay presencia de transporte público al interior del sector. El trazado geométrico no es el adecuado por: alta pendiente, anchos no aptos para doble circulación y un bajo radio de giro en algunas curvas. La vista 3D permite apreciar, aunque sin establecer medidas, la condición de elevación del terreno respecto a la zona baja del municipio (imagen 6).

\section{Imagen 4}

Localización del sector Carlos Pizarro, Soacha, Cundinamarca, Colombia. Municipio conurbado a Bogotá

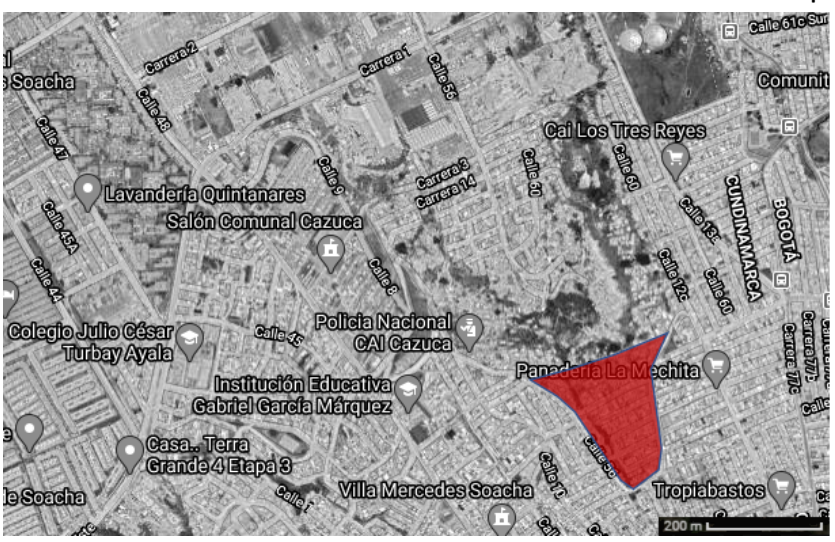

a. Sector Carlos Pizarro.

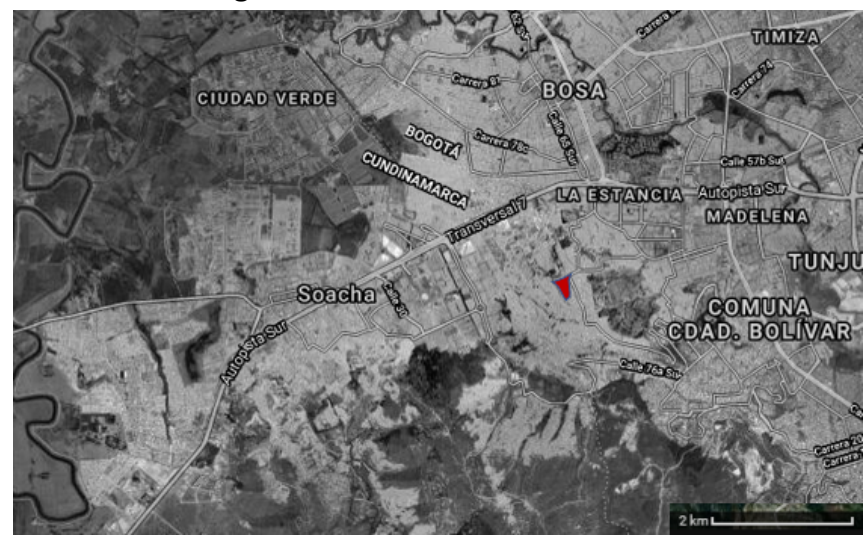

b. Ubicación del sector Carlos Pizarro.

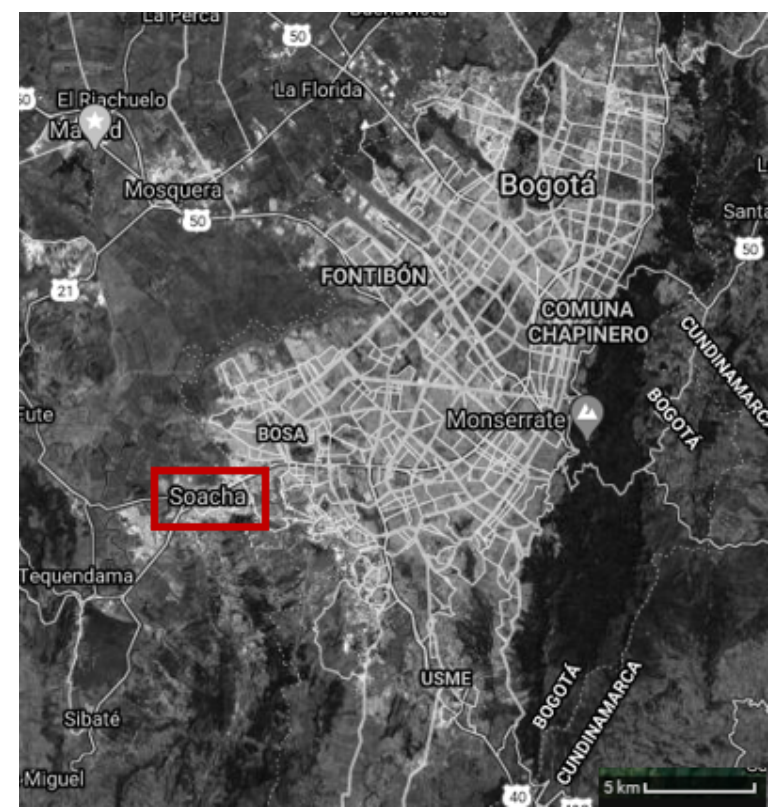

c. Ubicación del municipio de Soacha, respecto de la ciudad de Bogotá, Colombia

Fuente: Autores y Google Earth, 2020 
Imagen 5

Vía de acceso y vía principal del sector Carlos

Pizarro, Soacha, Cundinamarca, Colombia.

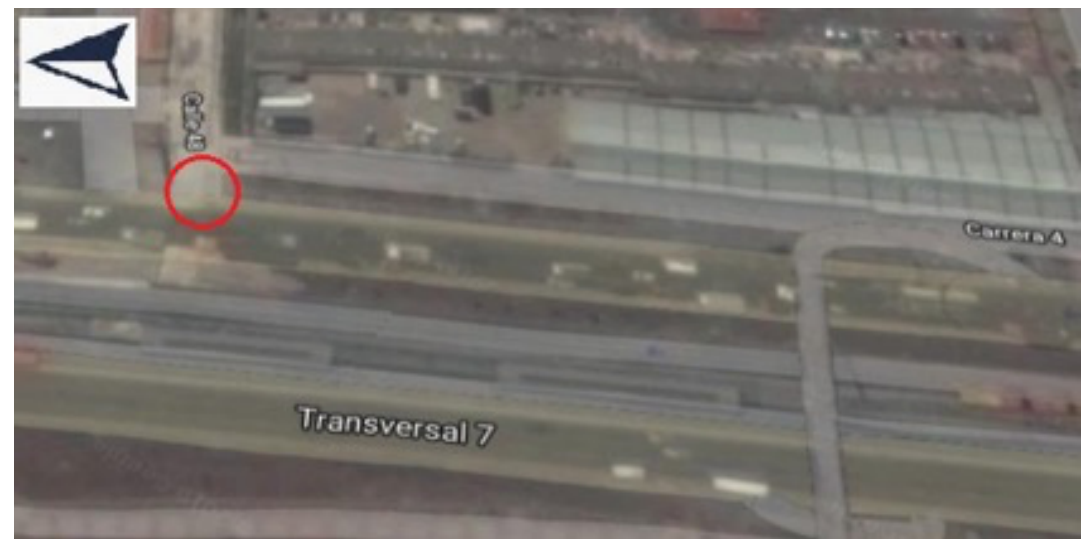

a. Ubicación de la vía secundaria que conduce al asentamiento.

Carrera 4 con calle 48, Soacha, Cundinamarca.

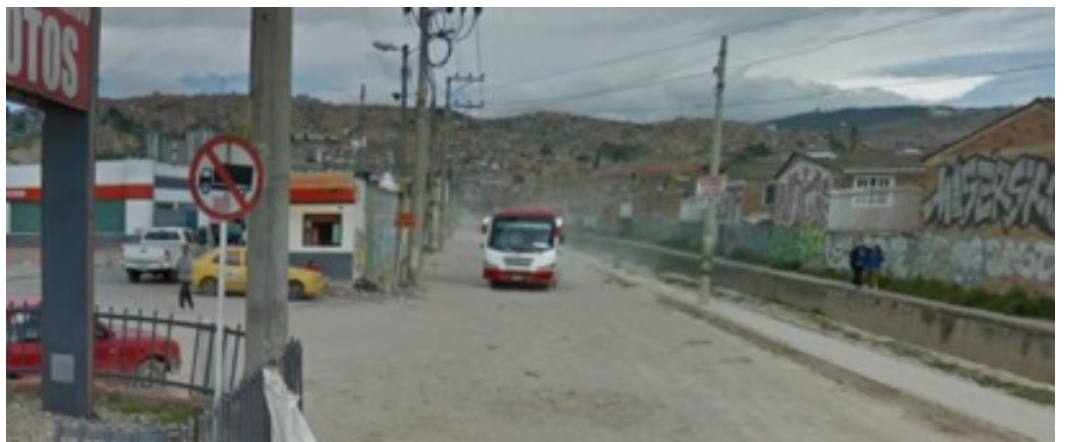

b. Tramo inicial sin tratamiento en la carpeta. Presencia de transporte público.

En el fondo de la imagen se aprecian los cerros donde se ubica el asentamiento.

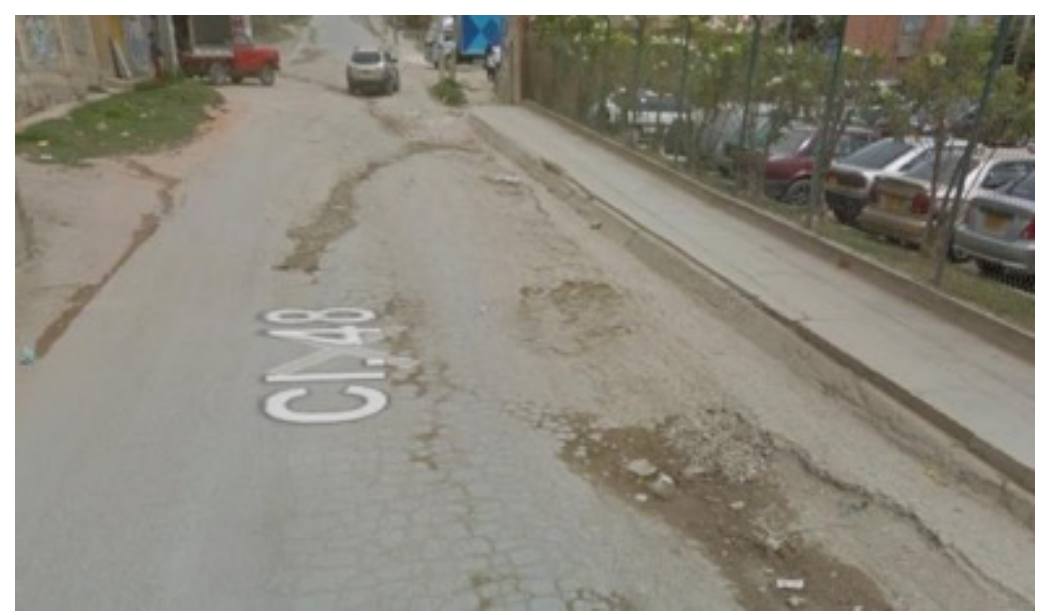

c. Avanzando por la calle 48 se encuentra la vía en pavimento rígido, aunque deteriorado, $\mathrm{y}$ visualmente se aprecia una pendiente $\mathrm{c}$ onsiderable de ascenso. No se observa presencia de sumideros $u$ otras obras de drenaje. Hay andén a un solo costado. 


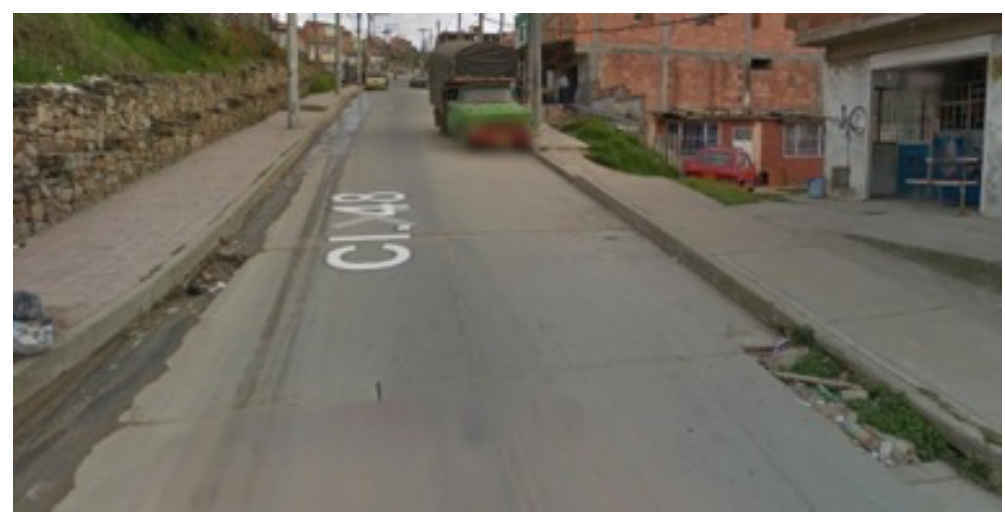

d. Metros más adelante por la calle 48 el pavimento rígido se aprecia en buenas condiciones. Sigue observándose una pendiente relativamente alta en el trazado. Hay andén a ambos costados y se aprecia sumidero.

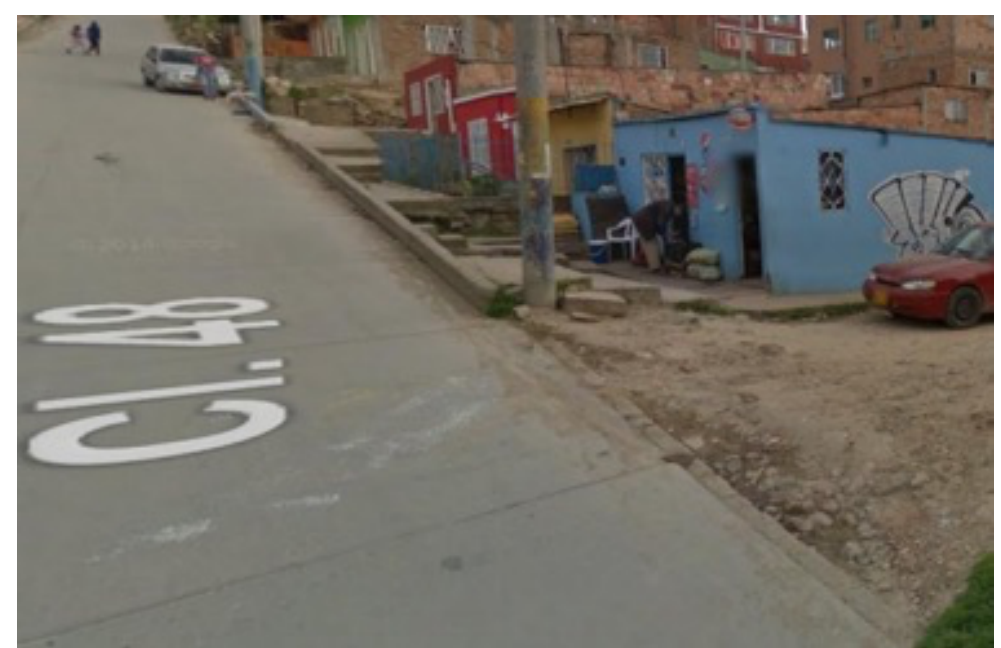

e. Las vías de conexión laterales a las viviendas no tienen tratamiento, son vías en tierra. Se aprecia que se acentúa la pendiente de la vía.

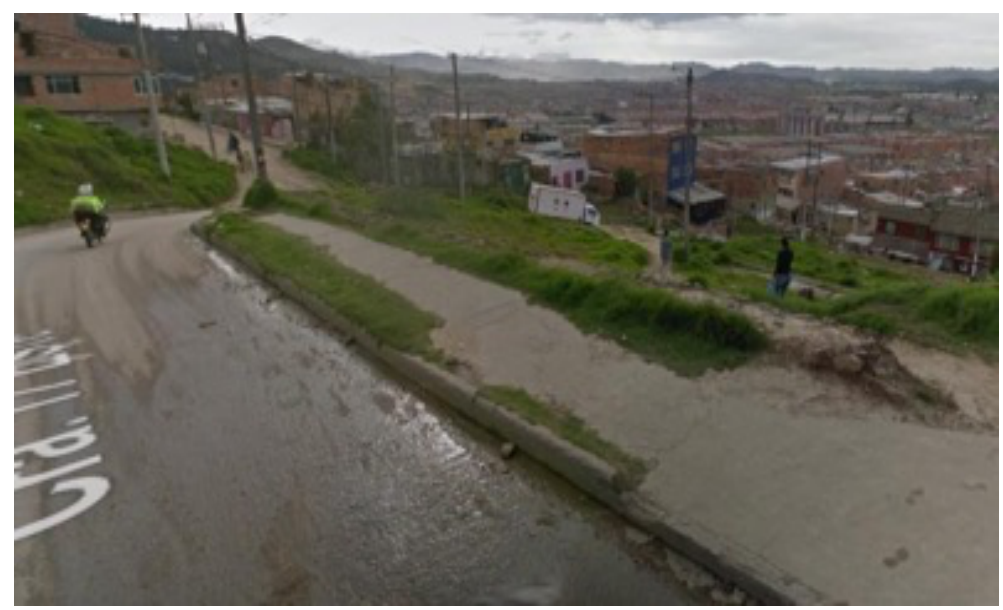

f. En ese punto se accede al sector Carlos Pizarro. La panorámica da cuenta de la elevación a que se encuentra con respecto a la zona centro del municipio (Soacha). 


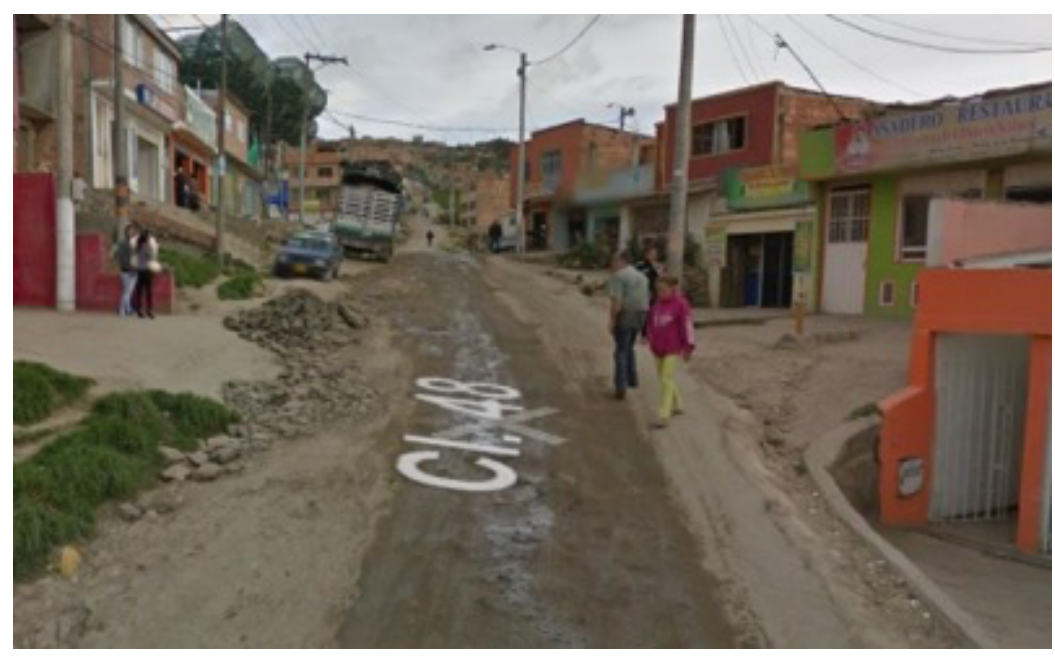

g. Los primeros tramos viales al interior del sector no tienen tratamiento y los andenes están seccionados por predios. No se aprecian obras para manejo de escorrentía.

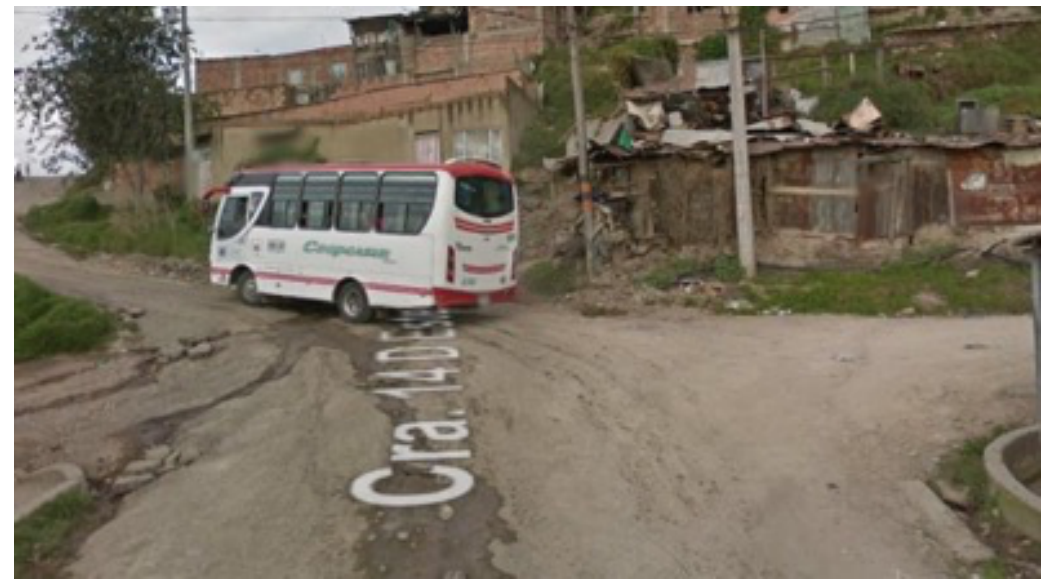

h. Al continuar hacia el interior del asentamiento la tendencia sigue siendo de vías en tierra, sin presencia de andenes ni obras para manejo de escorrentía. Se observa servicio de transporte público de baja capacidad, y la pendiente media sigue siendo alta.

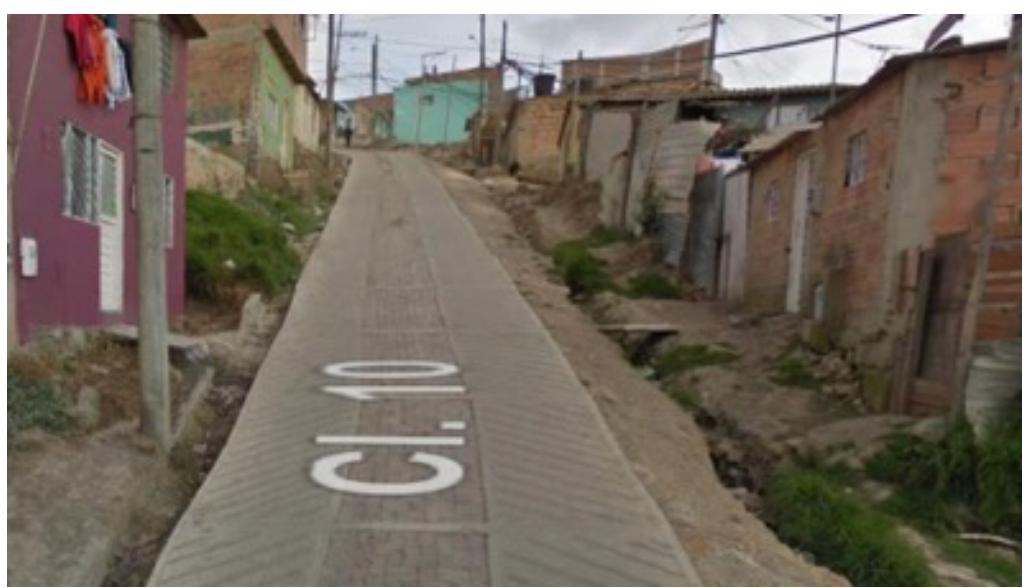

i. Culminando el trazado principal que atraviesa el asentamiento, se tiene un tramo con tratamiento en placa huella, pero no supera los $400 \mathrm{~m}$ y no presenta andenes. La pendiente ascendente se mantiene. La escorrentía se maneja por cárcavas.

Fuente: Google Maps, 2019. 
Con el aplicativo Google Earth se estableció el perfil de pendiente para la ruta de acceso principal al sector Carlos Pizarro (imagen 6). La información que proporcionó el perfil permitió hacer lectura de las condiciones de terreno y tiempos de viaje (complementando la información con los registros de seguimiento mediante GPS).

Imagen 6

Perfil de elevación de la vía de acceso al sector Carlos Pizarro.

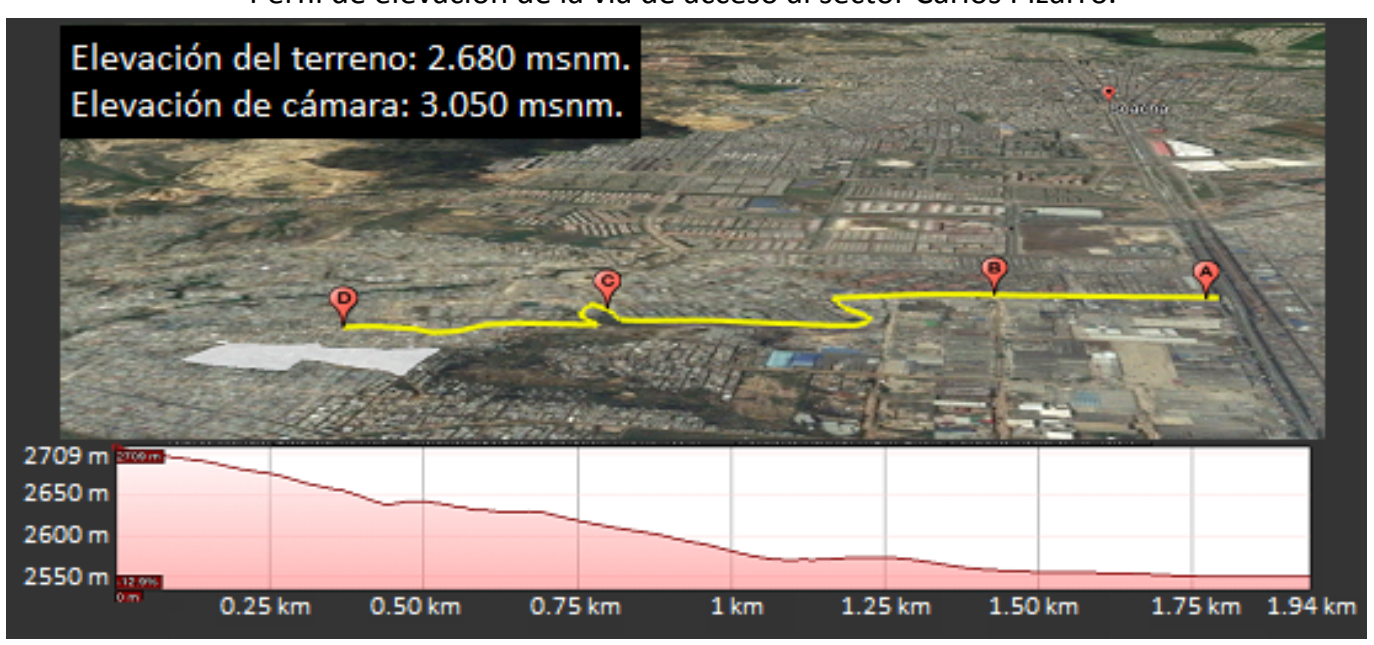

Fuente: Jurado y Zabala, 2019, a partir de Google Earth

\subsection{Datos de desplazamiento en las vías}

Para tener información de las condiciones de desplazamiento al transitar por la vía principa del sector, se realizó un seguimiento de ruta por GPS, mediante la aplicación Geotraker. Tras un recorrido realizado en transporte público, se obtuvo el siguiente perfil de velocidad (Imagen 7). El recorrido en transporte público se realizó en día laboral iniciando a las 8:50 a.m., tardó 10 minutos y tuvo una longitid de 1.97 km.

Imagen 7

Perfil de velocidad en la vía de acceso al sector Carlos Pizarro. Transporte público.

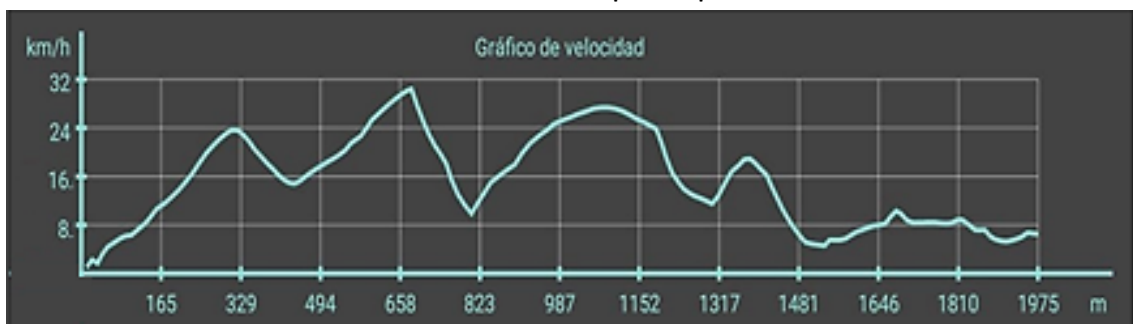

Fuente: Jurado y Zabala, 2019.

Con la información del perfil, se construye un mapa de calor para la vía en estudio (Imagen 8), en la cual se muestran los gradientes de velocidad demarcados con colores, siendo los tramos de color verde donde se alcanzó una velocidad máxima de $32 \mathrm{Km} / \mathrm{h}$, los tramos amarillos y naranjas $24 \mathrm{Km} / \mathrm{h}$ y $16.45 \mathrm{Km} / \mathrm{h}$, respectivamente, son representativos de una velocidad media, y por último los tramos en color rojo con la velocidad más baja, de 8.22 $\mathrm{Km} / \mathrm{h}$. 
Imagen 8

Mapa de calor para velocidad en la vía de acceso al sector

Carlos Pizarro. Recorrido en transporte público.

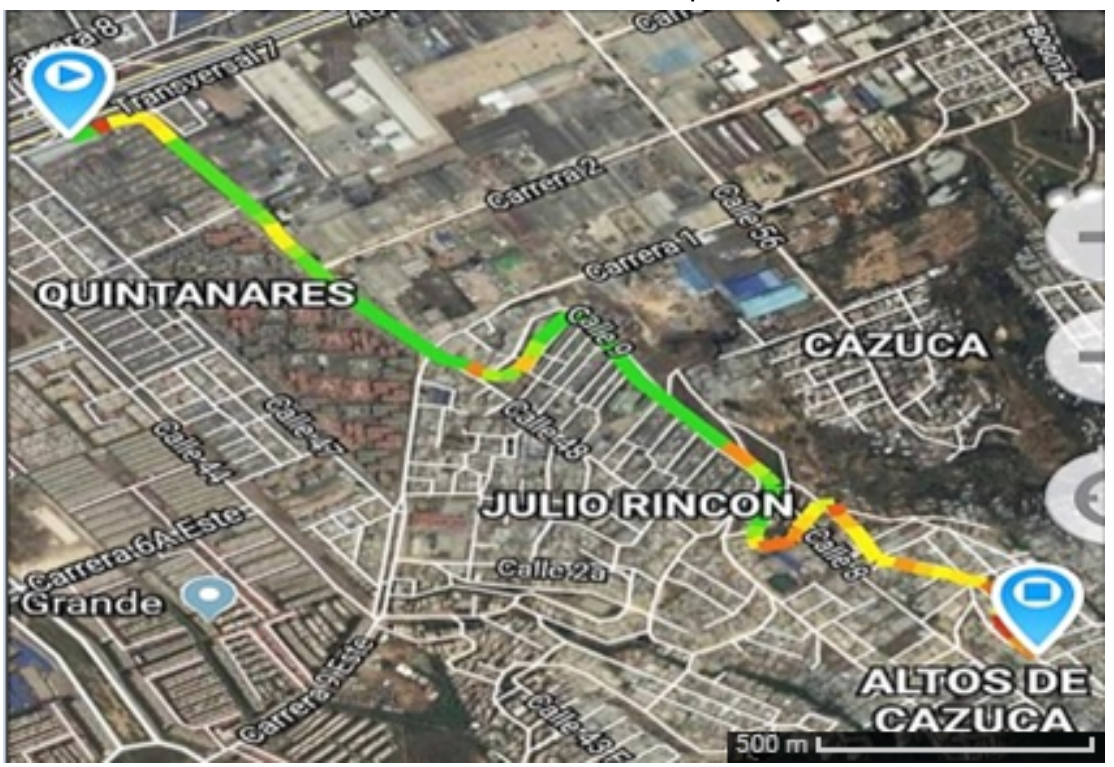

Fuente: Jurado y Zabala, 2019, a partir de Google Earth.

El aplicativo Geotraker (o similares) provee también el perfil de elevación en metros sobre el nivel del mar (m.s.n.m.) del trazado realizado (Imagen 9). Esta información permitió conocer la pendiente máxima obtenida: $25 \%$, y la pendiente media: $9 \%$. Estos registros evidencian un acceso complejo, que dificulta el tránsito vehicular (relacionado con las bajas velocidades obtenidas por los vehículos de transporte público), y aún más el peatonal.

Imagen 9

Perfil de elevación para la vía de acceso al sector Carlos Pizarro.

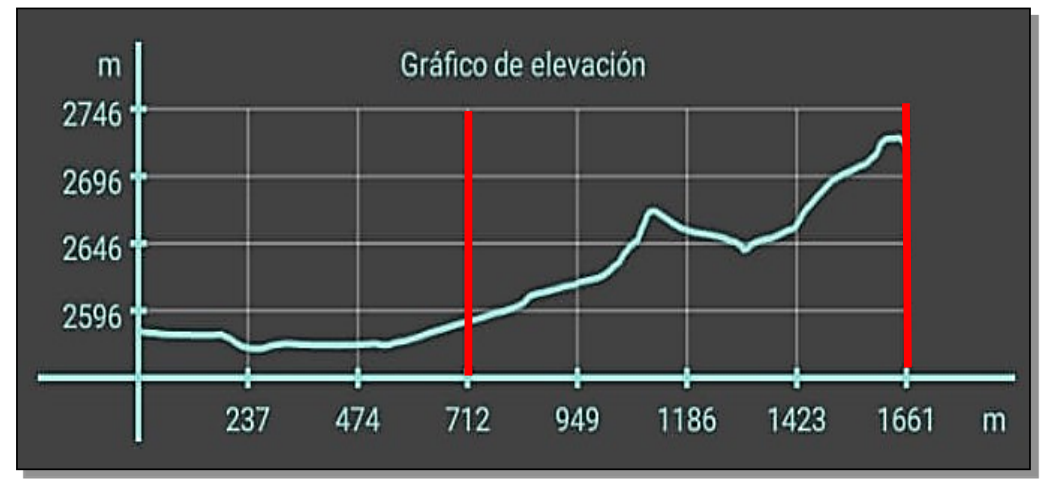

Fuente: Jurado y Zabala, 2019

\subsection{Registros de velocidad mediante radar}

Si bien se estableció previamente que el uso de GPS facilita el registro de velocidades media de desplazamiento, pueden corroborarse las cifras mediante datos obtenidos por medio de radar. Equipo aplicable tanto a velocidades vehiculares como peatonales (debe asegurarse que el radar a emplear registra velocidades por debajo de los $10 \mathrm{~km} / \mathrm{h}$ ).

La velocidad vehicular se midió por radar para diversas tipologías vehiculares presentes: automóvil, camión, bus y motocicleta. Los valores resultaron en el rango de 10 a $20 \mathrm{~km} / \mathrm{h}$, con un valor medio de $12 \mathrm{~km} / \mathrm{h}$, corroborando las cifras provenientes del estudio por GPS. 
Tal como anotaron Jurado y Zabala (2019), se obtuvieron datos de velocidad peatonal desde el inicio del recorrido (con la pendiente más baja: 4\%), y luego se repitió el procedimiento desde la zona de mayor altitud con pendiente del $25 \%$. En varios tramos viales no se contaba con ningún tipo de afirmado, había alta presencia de baches y de arrastre de material rocoso generado por escorrentía de aguas superficiales. También era frecuente la carencia de andenes y sardineles, obligando a los peatones a circular por la calzada, en medio de baches, material vegetal y exponiéndose a accidentes. Es importante aclarar que dadas las condiciones de la mayoría de las vías internas del asentamiento y la tasa de posesión vehicular, el tránsito de automóviles y motos es prácticamente nulo. Bajo el escenario descrito se registraron velocidades peatonales por debajo de los $2 \mathrm{~km} / \mathrm{h}$, una velocidad máxima registrada de $2.87 \mathrm{Km} / \mathrm{h}$ y velocidad media de $2.19 \mathrm{Km} / \mathrm{h}$. Las cifras anteriores son muy bajas si se tiene en cuenta que la velocidad media peatonal es de $4 \mathrm{~km} / \mathrm{h}$, en condiciones de terreno plano (pendiente menor al $3 \%$ ).

\subsection{Registros de imágenes por medio de Dron}

Es posible que debido a una amplia extensión territorial del asentamiento, no se considere viable para la toma de información, realizar un recorrido de toda la zona. Así que para obtener imágenes de las condiciones de vías que llevan a viviendas relativamente alejadas o de difícil acceso, se pueden emplear imágenes capturadas por medio de drones, o RPAS (de las siglas en inglés: Remotely Piloted Aircraft System, o sistema de navegación aérea no tripulado) (imagen 10). Estas imágenes permiten apreciar el estado o condición de la vía, la existencia de andenes, y realizar aproximaciones al ancho de vía.

\section{Imagen 10}

Fotografías tomadas por dron en el sector Carlos Pizarro.

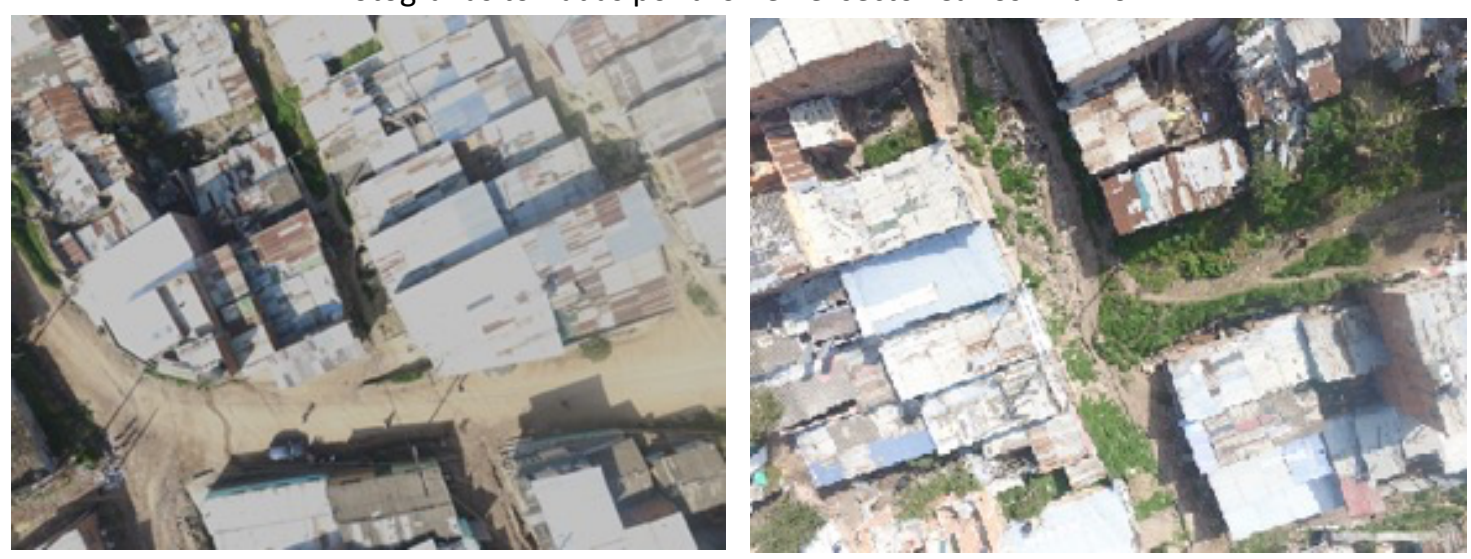

Fuente: autores (2019)

\subsection{Registros en video y uso de contadores digitales para aforo vehicular}

Otra variable importante para complementar el estudio de tránsito en las vías del asentamiento es el flujo vehicular. Con el fin de estar el menor tiempo posible en campo, se identificaron intersecciones relevantes en la vía principal y se procedió a grabar en video el flujo vehicular por un tiempo relativamente corto (2 horas). También se llevaron a cabo aforos por tipología vehicular, empleando aplicaciones para conteos disponibles en plataformas para teléfonos móviles.

Es evidente que con un tiempo tan corto de medición, ese aforo no reemplaza un estudio de flujo vehicular a realizarse durante un período de tiempo de al menos 8 horas diarias, y por varios días; pero si permite aproximar una cifra a priori de veh/h, más aún si se recuerda que el tránsito por sectores informales es relativamente bajo.

El resultado final del aforo estableció un flujo relativamente bajo en la vía principal: $60 \mathrm{veh} / \mathrm{h}$ en promedio, para cada uno de los 2 sentidos de circulación, con una distribución de: 43\% para automóviles, 20\% para buses, 6\% para camiones, $30 \%$ para motocicleta, $1 \%$ para bicicletas. 


\subsection{Encuestas sobre la percepción ciudadana respecto de la movilidad en el sector}

De manera complementaria al uso de tecnologías para teledetección, se entrevistó a miembros de la comunidad para recopilar criterios sobre las condiciones en que viven la movilidad cotidianamente. Tras realizar un muestreo estadístico se llevaron a cabo 70 encuestas.

De los resultados se destaca que el 36\% de los hogares están conformados entre 3 y 4 personas, un $24 \%$ entre 5 y 6 personas, un $20 \%$ entre 1 y 2 personas, y el otro $10 \%$ entre 7 y 9 personas. En la distribución de oficios se encontró que un $50 \%$ de las personas se encarga de tareas del hogar, un $20 \%$ son empleados, otro $20 \%$ independientes y el otro $10 \%$ están desocupados.

La mayor parte de la población del sector se transporta en bus de servicio público (70\%), un 14\% a pie, un $8 \%$ en moto, un $4 \%$ en bicicleta, y el otro $4 \%$ en medios informales o ilegales. Como puede apreciarse, la participación de vehículos particulares es muy baja (no se registran automóviles) y el porcentaje de caminatas es relativamente bajo, debido a la complejidad del trazado y distancia de acceso desde la vía principal; pues se tiene que la mayoría de los trayectos tardan entre 20 y 30 minutos, y solo una fracción de viajes tardan más de 40 minutos, con origen y destino el hogar.

Ahora, la necesidad que implican los desplazamientos por su motivo, son principalmente: trabajo (32\%), gestiones de compromisos como pago de servicios públicos (32\%), estudio (14\%).

Estos indicadores dan cuenta de la población que es usuaria de los sistemas de transporte, tanto por cantidad, selección modal, como por sus actividades.

Como complemento a la información socioeconómica, resultó que el 50\% de las familias tiene ingresos mensuales por debajo de 150 U\$, y solo un $12 \%$ supera los 250 U\$.

En cuanto a la percepción de los problemas generales del sector, se tiene que un $42 \%$ de los encuestados cree que el mayor problema es la mala calidad de las vías, un 34\% los problemas por falta de alcantarillado, un 14\% las inundaciones, un $4 \%$ dice que las condiciones del terreno, otro $4 \%$ que la falta de servicios públicos, y el $2 \%$ manifiesta que problemas de transporte. De manera general, el $68 \%$ de la población cree que las inversiones más urgentes en el sector deben enfocarse en el vías y transporte, y el otro $32 \%$ dice que a temas de vivienda.

Como puede apreciarse, el mayor porcentaje de la población considera que el transporte y la movilidad son los mayores problemas a solucionar.

\section{Conclusiones}

Los datos recopilados permitieron informar técnicamente las condiciones de movilidad y transporte en el sector, y así poder establecer su potencial evolución por medio de intervenciones en infraestructura por pate de las entidades oficiales de la municipalidad.

En el caso estudiado se concluye que es viable una mejora en las condiciones de transporte tras una intervención de las vías, especialmente de la de acceso al asentamiento, tanto a nivel de perfil geométrico (hay puntos con ancho insuficiente para el paso de 2 vehículos en sentidos opuestos, y pendientes que sobrepasan claramente el $12 \%$ recomendado como máximo), como en la mejora de la estructura de la vía (reparar las secciones deterioradas en el pavimento rígido, y extender esa pavimentación a los tramos donde no hay. También habría que complementar las obras referentes al tránsito peatonal, pues el trayecto es de gran longitud y la pendiente general no es apta para largas caminatas.

Respecto del alta pendiente en el trazado de la vía, pretender intervenirla para reducir su porcentaje resultaría contraproducente debido a que las viviendas ya se encuentran localizadas, y se generaría un desnivel entre la vía 
principal y las ortogonales de acceso a las viviendas. Esto requeriría de una serie de intervenciones que no facilitarían el tránsito vehicular a las vías de los costados, además de adecuaciones complejas para el manejo del saneamiento.

Se concluye que el uso de equipos de teledetección, aporta bases técnicas suficientes para concluir si se hace necesario o no continuar con estudios más específicos (como enviar una comisión de topografía) para adelantar el proceso de legalización.

Finalmente, la percepción de la comunidad respecto de las necesidades de mejora al asentamiento, dan mayor prelación al tema de transporte y movilidad; hecho que destaca la necesidad de este tipo de estudios como insumo para determinar las prioridades de intervención.

\section{Referencias bibliográficas}

Alvarado, S. (2014). Uso de un sistema de información geográfica para el análisis de amenaza por inundaciones en la cuenca alta del río Bogotá-municipio de cota-límites localidad de Suba. Trabajo final de grado, Universidad Católica de Colombia. 66 p. Recuperado de https://repository.ucatolica.edu.co/bitstream/10983/1800/1/Uso-SIG-para-an\%C3\%A1lisis-amenazainundaciones-cuenca-alta-r\%C3\%ADo-Bogot\%C3\%A1.pdf.

Atencia, V., Contreras, J.J., y, Vergara D. (2008). Estudio multitemporal de imágenes satelitales con fines de delimitación del complejo Bajo San Jorge margen izquierdo (B3) y diagnóstico de zonas intervenidas antrópicamente (agricultura y ganadería). Trabajo de grado, Universidad de Sucre, Sincelejo. Recuperado de https://repositorio.unisucre.edu.co/bitstream/001/935/1/T333.91814\%20A864.pdf.

Bazán, R., Corral, M., Pagot, M., Rodríguez, A., Oroná, C., Rodríguez, M. ... Busso, F. (2005). Teledetección y modelado numérico para el análisis de la calidad de agua en el embalse Los Molinos, Córdoba, Argentina. Revista Ingeniería hidráulica en México, Vol. XX, No. 2, p.p. 121-135.

Bogotá cómo vamos (s.f.). El problema de los asentamientos informales. Recuperado de https://bogotacomovamos.org/el-problema-de-los-asentamientos-informales/.

Borobio, M. (2009). Sistemas de información geográfica. Infraestructura básica para la planificación y el desarrollo de los asentamientos. Ingenieros sin fronteras Catalunya, Revista Cuadernos internacionales de tecnología para el desarrollo humano, (8), 1-16p.

Clichevsky, N. (2000). Informalidad y segregación urbana en América Latina. Una aproximación. Santiago de Chile, Serie medio ambiente y desarrollo de la Comisión Económica para América Latina y el Caribe (CEPAL), $61 \mathrm{p}$.

Clichevsky, N. (2006). Regularizando la informalidad del suelo en América Latina y el Caribe. Santiago de Chile, División de desarrollo sostenible y asentamientos humanos de la Comisión Económica para América Latina y el Caribe (CEPAL), $200 \mathrm{p}$.

Giraldo, M. (2013). SIG como herramienta de estudio y planificación del uso del suelo en zonas agrícolas. Universidad de Manizales, Revista Ventana Informática, (29), 111-128.

Guillén, C., Murugan, V., y, Dávila, M. (2014). Aplicación de teledetección y SIG para el levantamiento cartográfico de los suelos de la cuenca Solani, India. Revista Geográfica Venezolana, vol. 56, No. 2, Universidad de Los Andes, Mérida, Venezuela. Recuperado de https://www.redalyc.org/jatsRepo/3477/347743079003/html/index.html 
Gulyani, S., Talukdar, D., \&, Jack, D. (2010). Poverty, Living Conditions, and Infrastructure Access: A Comparison of Slums in Dakar, Johannesburg, and Nairobi. Policy Research Working Paper 5388, World Bank.

Jurado, J., y, Zabala, R. (2019). Diagnóstico de la movilidad en el barrio Carlos Pizarro, comuna cuatro, municipio de Soacha. Trabajo final de carrera como parte del proyecto de investigación "Apropiación de herramientas para teledetección en el reconocimiento de condiciones urbanísticas en asentamientos carenciados". Universidad de La Salle, Bogotá, 170 p.

Koch, J., Lindau, L.A. \&, Nassi, C.D. (2013). Transportation in the Favelas of Rio de Janeiro. Lincoln Institute of Land Policy. Recuperado de https://www.lincolninst.edu/publications/working-papers/transportationfavelas-rio-janeiro.

Lincoln institute of land policy (2006). El desafío de la formación de asentamientos informales en los países en vías de desarrollo. Recuperado de https://www.lincolninst.edu/es/publications/articles/el-desafio-laformacion-asentamientos-informales-en-los-paises-en-vias.

Lincoln institute of land policy (2019). Solutions in slums. Amid substandard living conditions, glimmers of hope. Recuperado de: https://www.lincolninst.edu/publications/multimedia/podcast-solutions-slums.

Manzané, B., Fiol, I., Camaño, N., Vega, N. y, Alarcón, J. (2019). Aplicación de la teledetección para el análisis de vías de acceso hacia asentamientos informales. Revista de Iniciación Científica RIC, Universidad Tecnológica de Panamá, 5(2), 8-14.

Nadal, L. \&, Linka, C. (2018). Minha Casa Minha Vida (MCMV), Access and Mobility: A Case for Transit-Oriented Low Income Housing in Rio de Janeiro. Lincoln Institute of Land Policy. Recuperado de https://www.lincolninst.edu/sites/default/files/pubfiles/nadal_wp18ln1.pdf.

Organizaciones de las Naciones Unidas (ONU) (2015). Temas Hábitat III. Asentamientos informales. Conferencia de las Naciones Unidas sobre vivienda y el desarrollo urbano sostenible. New york, 10p. Recuperado de http://habitat3.org/wp-content/uploads/Issue-Paper-22_ASENTAMIENTOS-INFORMALES-SP.pdf.

Pérez, M. (2009). El uso de las TIG en los barrios informales: una herramienta indispensable de evaluación y planificación. Ingenieros sin fronteras, Catalunya, Revista Cuadernos internacionales de tecnología para el desarrollo humano, (8), 1-11.

Renny, M. (2009). Access to Transportation for the Urban Poor in Indonesia. Institute for Transportation Studies, UN-Habitat Global Energy Network for Urban Settlements (GENUS).

Setty, V. (1997). Urban poor and urban transport. Their mobility and access to transport services. International Forum of urban poverty, Florence, Italy. UN-Habitat. Recuperado de https://www.researchgate.net/publication/311950238_Urban_Poor_and_Urban_Transport_Their_Mobilit y_and_Access_to_Services.

Starkey, P. \&, Hine, J. (2014). Poverty and sustainable transport. How transport affects poor people with policy implications for poverty reduction. UN-Habitat, $68 \mathrm{p}$. Recuperado de https://sustainabledevelopment.un.org/content/documents/1767Poverty\%20and\%20sustainable\%20tran sport.pdf

Techo (s.f.). La realidad de los asentamientos. Recuperado de https://www.techo.org/colombia/plataformaasentamientos/ 
UN-Habitat (2006). The State of the World's Cities Report. Earthscan, Nairobi, 202 p. Recuperado de https://sustainabledevelopment.un.org/content/documents/11292101_alt.pdf.

UN-Habitat (2012). Streets at tools for urban transformation in slums: a street- led approach to city wide slum upgrading. Nairobi, 97 p. Recuperado de https://www.ohchr.org/Documents/Issues/Housing/InformalSettlements/UNHABITAT_StreetsasToolsforU rbanTransformationinSlums.pdf.

Urazán, C.F. (2008). El rol de los servicios públicos básicos en las formas de crecimiento urbano. Estudio de la ciudad de Cúcuta, Colombia. Universidad Politécnica de Cataluña. Barcelona, 250 p.

Urazán, C.F. y, Magrinyá, F. (2015). El rol de los servicios urbanos en la legalización predial y la generación de calidad urbana y valor del suelo. Aplicación al caso de Cúcuta (Colombia). Revista Hábitat y Sociedad, (8), 113-145.

Tamayo, S. (2019). Aplicabilidad del SIG en la legalización de asentamientos de origen informal. Caso La Libertad, Pereira, Colombia. Universidad de Salzburgo. 145 p. Recuperado de https://issuu.com/unigis_latina/docs/tesis_tamayo1.

Esta obra está bajo una Licencia Creative Commons Attribución-NoCommercial 4.0 International

\section{(cc) EY-NC}

